Orer the superior part of the left parietal bone, the scalp was swollen and discoloured to the extert of a half-crown piece; it had very much the appearance of one of those ganguineous tumours or cephalhæmata which are occasionally formed upon the presenting part of the head, in consequence of pressure. On pressing upon it with the finger, clot could be felt beneath the scalp, and, in the centre of this, an irregularity in the bone, which might have been caused either by a bony ridge or a fracture. The head was then opened, and the parietal bone, which was fractured, removed. On examining its inner surface, a clot of blood, rather larger than a shilling, and about a third of an inch thick in the centre, was seen between the dura mater and bone at the seat of the injury. An incision was then made into the external tumour, which laid bare a small clot between the pericranium and bone. On washing away this clot, we discovered beneath it a fissure in the parietal bone, of about an inch and a half in length. Upon that part of the surface of the brain which corresponded to the injury, the vessels of the pia mater were nuch congested. With this exception, there was no other morbid appcarance in the brain, or in any other of the viscera which we subsequently examined. In accordance with my instructions, Mr. Coster stated, in a certificate, that the cruse of death was fracture of, and effusion of blood beneath, the cranium, the result of a fall during birth.

A coroner's inquest was subsequently held upon this case, partly in consequence of our certificate, and partly because the suspicions of the neighbours were excited respecting the cause of death. The woman was unmarried, and had twice before given birth to illegitimate children. I can say very little about this inquest, as, having received no notice of it, neither of us was present; nor could we find any account of it in the Bristol papers. I believe, however, the verdict returned was in accordance with the certificate which we had given of the death.

REMarks. This case presents some features of interest, especially in a medico-legal point of view. The time which clapsed, namely, six days, between the occurrence of the injury and the supervention of convulsions, is worthy of notice. The symptoms produced were not those of compression, properly so called, but rather such as would arise from irritation of the grey matter of the brain; and they do not appear to have been developed until the clot effused underneath the dura mater had acquired a certain degree of hardness. The convulsive attacks were in many respects analogous to those epileptic seizures which we see in the adult, as a result of pressure upon the brain from bony growths, tumours, etc.

Had it been possible to arrive at a correct diagnosis of the nature of the injury during life, the case would, I think, have justified surgical interference. The cranium might have been trephined over the fracture, and the clot removed with some prospect of success, provided the operation had been performed sufficiently early, before the symptoms of cerebral irritation had become fully developed.

In a medico-legal point of view, the case is interesting, as it shows that fracture of the child's cranium may sometimes be a result of delivery in the crect posture.

This is a subject which has been much discussed by medical jurists. Chaussier performed some experiments on the bodies of still-born children, allowing them to fall with their heads downwards on a paved floor, from a height of eighteen inches; and he found that out of fifteen cases, one or other parietal bone was fractured in twelve. On the other hand, the cases collected by Dr. Klein, of Stuttgardt, show that fractures of the cranium as a result of delivery in the upright posture are exceedingly rare. Out of 183 cases, in which the women were rapidly delivered whilst standing, sitting, or kneeling, not one child died nor did any fracture of the bones or severe external injury take place. The explanation of this discrepancy between the results of cases which have actually occurred, and of analogous experiments which have been performed, may, I think, be found in the circumstance that when delivery takes place in a standing posture, the child falls obliquely instead of directly downwards, in consequence of its following the direction of the vaginal canal which is obliquely downwards and forwards, especially near the os externum. It thus becomes expelled forwards against the clothes of the mother, and these, as well as the umbilical cord, serve to break the violence of its fall. Still, howerer, if we can credit the testimony of the woman and those around her, the instance I have just related proves that fracture of the cranium may occasionally result from such accidents. Although the character of these witnesses is by no means above suspicion, yet the circumstantial evidence tends to corroborate their testimony. The cord had all the appearance of having been broken and not cut. According to the account of the woman who was present at the delivery, the child was taken up from the floor, beneath a tablc upon which the mother was leaning at the time of its birth: and we find accordingly that the injury was exactly of that kind and in that situation where we should expect it, when a child falls upon the floor with its head downwards. There appears to have been no ground for supposing that it was intlicted by the mother or any other person present, for the purpose of destroying the child : for, had it been so, it is most improbable that the party inflicting it should not have proceeded to further violence, but have remained satisfied with the result of a blow which caused no appreciable symptoms at the time. Such a view appears to have been taken by the coroner's jury, who, by their verdict, acquitted the parties of any such intention.

Clifton, Bristวl, October 1853.

SINGULAR CASE OF ALOPECIA.

By JOHN I:ARCLAY, M.D., I'hysician to the Leicester Infirmary.

[Read at the Meeting of the Midland Branch of the Association, at Leicester, on Sept. 1st, 185:3.]

Mr. A. B. applied to me in February last on account of complete baldness. He is twenty-four years of age, a printer, of florid complexion, sanguine temperament, steady habits, and married.

He had been working hard in a close and confined room seven months previously, when he noticed the hair begin to fall from the scalp. This was soon denuded, and then his beard and whiskers followed. The hair on the pubes and in the axillax, on the arms and legs, next disappeared, and lastly, the cycorows and cyelashes, so that when I saw him, he was perfectly hairless from head to foot.

Ilis general health was considerably affected; his appetite was good; but the digestion impaired; and he complained of a sensation of languor and general debility. The excreta were normal. I ordered him a preparation of steel, and friction of the scalp, with a stimulating liniment. The form in which I prescribed the latter was two drachms of tinctura lytta to half a pint of rosemary water, which I have usually found a very successful remedy:

In three or four weeks, he found the smarting cease to be produced by this strength of the lotion, and there was no improvement in the state of the skin. I directed him to increase the proportion of the tinctura lytta at his own discretion.

By the end of the second month of treatment, he had gradually come to use pure tinctura lytta for friction to the head, the skin of which was totally insensible to its effects, while the fingers smarted considerably while applying it.

He has continued the intermal remedies with slight intermissions up to the present time, with very marked benefit to his general health, which is now quite reestablished; but there is not the slightest appearance of a return of the hair on any part of the body. When examined with a lens, the bulb of the hair seems gone, but the aperture through which the hair penetrated the cuticle remains. There is a slight down upon the ears, which has never disappeared; but with this exception, he remains perfectly hairless. 
I have recommended see air and bathing, but this is difficult of attainment to one dependent on his own industry in the Midland Counties.

It is the only case of complete alopecia I have ever met with in the course of my practice; and I am not aware of any recorded instances.

Leicester, September 1st, 1859.

\section{PFRISCOPIC REVIEW.}

\section{THGROSCOPICAI DISCOVERT.}

MUSCCLAR TISSUF OF THE HUMAN SKIN.

In the fourth number of the Journal of Microscopical Science, Mr. Joseph Lrster gives interesting confirmation of Kolliker's account of the muscles of the true skin.

Portions of the skin having been partially dried, and then cut into thin slices, exhibit, when again moistened, delicate bands of unisis, close to of unstriped muscle, rising in the epithelium, and thence descending obliquely, to be inserted the epithelium, alicles. "The muscles are seen to arise in all cases from the most superficial part of the corium, and to pase down obliquely to their insertions into the hair follieles immodiately below the sebaceous glands." In sections made as above described, it is at once remarked, that all the muscles (a $1, a 2$, described, it is at once remarked, that are on the same side of the resperich slopes. This arrangement of the muscles is exactly that which is best adapted for erecting as well as protruding the hairs, which must be drawn by the ir contraction nearer to the perpendicular. That this erection as well as protrusion of the hairs does occur, our author has satisfied himself by artificially exciting the state of "cutis anserins" on his own arm and leg. Tickling a neighbouring part will often induce horripilation; and if the eye is. kept on an individual hair at this time, it is seen to rise quickly. as the skin becomes rough, and to fall again as the horripilation subsides. Each hair-follicle of the scalp possesses but one muscle. Mr. Lister has not been able to confirm Henle's statement that muscular fibres exist in parts of the skin destitute of hair, such as the palm and the sole.

From these researches, it is obvious that there exists an intra-dermal muscular tissue, the function of which is to move the hair follicles, and perhaps, by some degree of pressure, to stimulate the glands which lie close to the muscles to increased secretion.

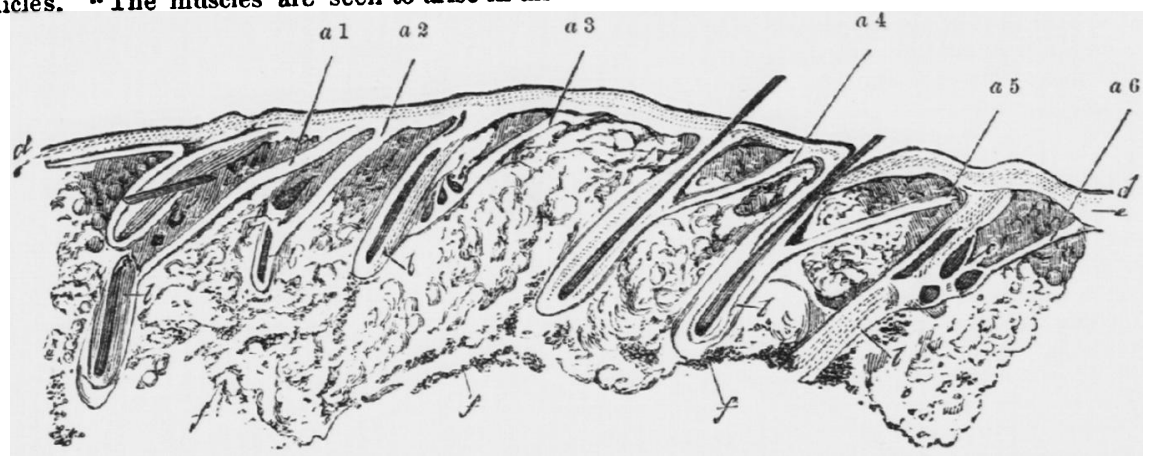

\section{GLANDS IN CONNEXION WITH THF FYE AND NOSE.}

Dr. SAPPEY has published, in the recent numbers of the Gazette Médicale (Nos. 33, 34, 35), some researches on the glandular secreting apparatus of the eye and nostrils.

He describes the orbital and palpebral portions of the lachrymal gland as usual, and states that the ducts passing from the former, to the number of three, four, or five, pass through the inferior division of the gland, on their way to the conjunctiva, and receive in this course the secretion of some of the lobules of that part of the organ; while the greater part of these lobules pour their secretion into two or three separate ducts, which pierce the conjunctiva in a line with those before mentioned. The acini of the lachrymal gland Dr. Sappey has succeeded in injecting with mercury.

The subconjunctival glands are from ten to twenty-five in number, conglobate: and each pours its secretion by the duct upon the surface of the membrane, whore it is reflected from the lid upon the eyeball at its upper nasal aspect. 'The ciliary scbaceous glands are two to each eyelush, and quite resemble the sebaceous glands of the hairs in other parts of the body : it is these, and not the Meibomian glands, which pour out the secretion so usually noticed in ophthalmia tarsi.

The mucous secretion of the nose is poured out, according to Dr. Sappey, not from follicles, but from glands, not unlike in general arrangement to the Meibomian glands of the evelids. They consist of grape-like bunches of acini, arranged along the excretory duct, into which they pour their secretion by short subsidiary branches. The main ducts run vertically through the mucous membrane, and open by circular orifices on its surface. In some parts of the nasal mucous membrane, as on the anterior part of the outer wall of the nostrils, they are very numerous; in others, more widely scattered. Our author has not succeeded in finding these glands in the thin membrane of the frontal and maxillary sinuses.

\section{BLOOD.VESSELS OF THE LUNGS.}

Dr. JAmes Newton Beai.e has submitted to the Royal Society (Phil. Mag., September) the results of a series of careful injections of the pulmonary and bronchial vessels, which, he finds, have no communication whatever with one another; and the most novel result of his investigations is, that the so called bronchial artery does not supply the bronchi at all.

The nulmonary artery may be thoroughly injected without the fluid passing in the least degree into the "bronchial " vessels, and vice versat.

I. The pulmonary artery makes no anastomosis whatever with any other artery, nor do its own branches anastomose with one another; its lianches are distributed directly to the aircells, and none gn to any of the other tissues of the lungs, excent some few which perforate the subpleural cellular tissue, and are distributed to the pleura; some of these also cross the posterior mediastinum, beneath the pleura, and reach the thoracic pleura.

Ir. 'The bronchial arteries end in veins, which ramify in the sulppleural cellular tissue; the cellular tissue of the lung heing the part supplied by these ( so called) bronchial vessels. The greater part of these bronchial veins pass into the posterior mediastinum, and empty themselves into the osophageal and other veins.

III. The bronchial mucous membrane is very freely supplied with a very close plexus of vessels, of a peculiar and very characteristic description, which is found to ramify in every part of racteristic descriptones, even as high as the trachea. The the bronchial membranes, eren as high as the trachea. The the air-cells, and therefore derived from the pulmonary artery, the air-cells, and therefore de branch of that vessel goes directly to the inucous membrane.

1v. The pulmonary veins are formed by the junction of two distinct sets of rndicles: one set derived from that part of the air-cells most distant from the minute terminal bronchus enterair-cells most distant whom ralicles form small trunks visible on the surface of the lung between the lobules. The other set is derived from the bases of the pulmonary lobule, and go to supply the bronchial mucous nembrane before entering the pulmonary vein.

v. The coats of the lymphatic vessels of the lung are supplied by blood-vessels derived from the air-cells, and which terminate in the pulmonary veins; and the distribution of blood-vessels on the coats of the lymphatics bears a strong resemblance to that of the capillaries on the bronchial mucous membrane. 